In: Diarrhoea and Malnutrition In Childhood.

Walker-Smith, J.A. McNeish, A.S. (eds.),

Butterworths, London, pp. 68-78, 1986.

\title{
Intestinal parasites
}

\section{Part 2 \\ Giardiasis: impact on child growth}

M.J.G. Farthing, L.J. Mata, J.J. Urrutia and R.A. Kronmal

Chronic disorders of the gastrointestinal tract may impair physical growth during infancy and childhood. Growth retardation has been particularly well documented in children with Crohn's disease ${ }^{12.33}$ and coeliac disease ${ }^{12.47}$ in which growth retardation may occur in the absence of gastrointestinal symptoms. Recurrent and persistent infection in infancy and childhood is also associated with growth retardation, the major offenders being infections of the respiratory and gastrointestinal tracts ${ }^{24.31}$. The pathogenic mechanisms of growth disturbance in chronic disease are poorly understood. Possible candidates include reduced dietary intake as a result of anorexia, food withholding following cultural practice or physician's advice and increased energy expenditure associated with fever and infection ${ }^{16,29}$. Nutritional deprivation due to intestinal malabsorption is probably a less important factor in inflammatory bowel disease ${ }^{14}$ but may be more relevant in coeliac disease and infective disorders of the intestine.

Although Giardia is now an established intestinal pathogen its relationship to child growth and development has not been clearly defined. However, giardiasis

(1) frequently affects infants and children:

(2) is known to cause morphological damage of the small intestine and malabsorption of a variety of nutrients ${ }^{15}$;

(3) is not always a self-limiting infection and may persist for many weeks or months ${ }^{34.46}$

(4) has been shown to impair physical growth in some individuals with Giardia infection $^{25,46}$.

There is, however, very little population-based data on the effect of Giardia infection on physical growth during infancy and childhood and thus the impact of this parasite at a community level is largely unknown. The parasite may be excreted by apparently asymptomatic individuals and thus before widespread strategies for the control of this infection are introduced the extent of its clinical impact must be established.

\section{Giardia and growth-historical aspects}

Although Giardia was first seen with the aid of a hand lens more than three centuries ago, it is only during the last 50 years that its pathogenicity for humans 
has been clearly established. In 1921, Herbert Perkins, then pathologist to the Paddington Green Hospital, was probably the first observer to associate impairment of growth with Giardia infection ${ }^{35}$. He described a child with recurrent diarthoea for 6 years, in whom Giardia was the only aetiological agent identified.

Five years later Reginald Miller, a physician at the same hospital, reported 23 cases of giardiasis in infants and childre ${ }^{34}$. The vast majority had chronic diarrhoea, the longest history being 10 years. At least eight of these 23 children were below their expected weight and height. Miller concludes that some children with giardiasis are "considerably below their proper weight and occasionally will produce retarded development and diminution in growth'. He also states that 'this (giardiasis) can mimic coeliac syndrome more than any other disease'. We cannot be certain, however, that giardiasis in these children was the primary disease since effective antigiardial therapy was not available at this time. In addition, the criteria for the diagnosis of coeliac disease had not been clearly established and thus this condition cannot be confidently excluded as a cause of these children's symptoms. The similarities between giardiasis and coeliac disease were again reiterated in 1938 by Veghely ${ }^{46}$ and later by Cortner'; the latter's monograph was titled 'Giardiasis: a cause of coeliac syndrome".

Thus for a number of years it has been evident that in individual cases chronic Giardia infection may be associated with growth retardation. Whether Giardia was the sole aetiological agent in these cases is not clear and the overall prevalence of growth disturbance in giardiasis cannot be determined from any of these studies.

\section{Evidence for growth impairment in giardiasis}

\section{Natural and experimental infections in animals}

Giardia infection in animals produces a variety of effects on physical growth depending on the species and age of the animal, and possibly the strain of Giardia (Table 9.5). Several reports have suggested that natural Giardia infections in dogs can result in weight loss and growth retardation, particularly when infection occurs during the first few months of life ${ }^{1.10}$. However, these findings are by no means

Table 9.5 Giardiasis and growth retardation-animal studies

\begin{tabular}{|c|c|c|}
\hline Study & Animal & Growth retardation \\
\hline \multicolumn{3}{|l|}{ Natural: } \\
\hline Bemrick $^{3}$ & Dog (mongrel) & - \\
\hline Barlough' & Dog & + \\
\hline Box $^{5}$ & Budgerigar & + \\
\hline \multicolumn{3}{|l|}{ Experimental: } \\
\hline $\begin{array}{l}\text { G. Vambia } \\
\text { Fantham and Porter }\end{array}$ & Cat & G. lamblia \\
\hline Fantham and Porter ${ }^{13}$ & Mouse (adult) & \pm \\
\hline Bemrick $^{3}$ & Dog (mongrel) & NR \\
\hline \multirow[t]{2}{*}{ Sehgal et al. ${ }^{41}$} & Rat (adult) & - \\
\hline & Rat (weaning) & + \\
\hline Hewlett ef al. ${ }^{22}$ & Dog (mongrel) & - \\
\hline Hill et al. ${ }^{23}$ & Mouse (suckling) & - \\
\hline \multicolumn{3}{|l|}{ G. muris } \\
\hline Roberts-Thomson et al. ${ }^{37}$ & Mouse & + \\
\hline
\end{tabular}


universal since Bemrick in 1943 reported that his naturally infected mongrel dogs came to no harm during Giardia infection ${ }^{3}$. An epidemic of giardiasis recently occurred in young budgerigars in some aviaries in Texas ${ }^{5}$. The infection had a profound effect on growth and development and birds were described by one aviary owner as 'going light' with a mortality of $70-100 \%$.

Some of the earliest experimental Giardia infections in animals were produced by Fantham and Porter ${ }^{13}$, using cysts from giardiasis sufferers returning from the Eastern Mediterranean war in Gallipoli. They successfully infected six kittens, all of whom failed to gain weight at the same rate as uninfected litter mates. The majority of these animals had severe infection from which they died. These workers also infected adult mice and found that growth retardation was proportional to the severity of the infection. However, a recent study of experimental Giardia lamblia infection in suckling albino CF-1 mice produced a self-limiting illness lasting 17-21 days without any effect on growth ${ }^{23}$.

Experimental $G$. lamblia infection in adult albino rats also had no effect on body-weight, although infection in weanling animals produced marked weight $\operatorname{loss}^{40}$. The authors of two recently described animal models of $G$. lamblia infection in gerbils and rabbits failed to report on the effect of this infection on growth and development ${ }^{2,39}$. Body-weight was reported to have been maintained during experimental infection in mongrel dogs ${ }^{22}$, although in infected puppies less than 6 months of age one would have expected weight gain.

Swiss albino mice have also been experimentally infected with the rodent parasite Giardia muris, when it was shown that impairment of growth and development was directly related to the number of cysts used to initiate infection ${ }^{37}$. Weight gain of mice infected with 10000 cysts was reduced by $40 \%$ compared with healthy control animals.

Thus there is evidence that Giardia impairs growth and development of both naturally and experimentally infected animals, although there are clearly inconsistencies in the reported data. In many of the above studies there are numerous uncontrolled variables such as the genetic background of the animal and the morphological type and strain of Giardia used to initiate infection. Despite these difficulties it would appear that Giardia infection does have an impact on growth of young animals, particularly after cessation of breast-feeding.

\section{Human Giardia infection}

Since the early observations of Perkins ${ }^{35}$ and $\mathrm{Miller}^{34}$ in the UK there have been a number of reports of the effect of Giardia infection on growth and development in infancy and childhood from Europe, Australia and the USA (Table 9.6). All were essentially retrospective studies of hospital populations and the majority involved relatively small numbers of patients. Growth and developmental data were generally incomplete, the majority of authors only reporting weight change as the index of growth. Veghelyi ${ }^{46}$ reported observations on 92 children; $86 \%$ had below average weight and $13 \%$ were below average height. This study still represents a major contribution to the literature on giardiasis in childhood and has only been significantly added to some 40 years later by a similar study from Australia ${ }^{25}$. Of 154 children diagnosed as having giardiasis by duodenal intubation and biopsy, $31 \%$ had either lost weight or failed to grow. Twenty-four of these children were followed up after antigiardial chemotherapy and 19 gained more weight than would have been expected from percentile growth charts, indicating that Giardia had 
Table 9.6 Giardiasis and growth retardation - human stndles

\begin{tabular}{|c|c|c|c|c|c|}
\hline \multirow[t]{2}{*}{ Study } & \multirow[t]{2}{*}{ Location } & \multirow[t]{2}{*}{ Subjects } & \multicolumn{3}{|c|}{ Growth retardation (\%) } \\
\hline & & & Weight & & Height \\
\hline Perkins $^{35}$ & UK & 7 & NR & 14 & NR \\
\hline Miller $^{34}$ & UK & 23 & 39 & & + \\
\hline Veghelyit' & Hungary & 92 & 86 & & 13 \\
\hline Boe and Rinvik ${ }^{4}$ & Norway & 22 & NR & 9 & NR \\
\hline Cortner" & USA & 4 & 100 & & 75 \\
\hline Court and Anderson" & Australia & 13 & 92 & & NR \\
\hline Burke ${ }^{6}$ & USA & 7 & 100 & & NR \\
\hline Kay, Barnes and Townley ${ }^{25}$ & Australia & 154 & NR & 31 & NR \\
\hline Pugh and Newton ${ }^{36}$ & UK & 17 & NR & 41 & NR \\
\hline
\end{tabular}

NR $=$ not reported

made a significant contribution to their weight loss or failure to thrive. Several other studies confirm the association between giardiasis and weight loss or failure of adequate weight gain ${ }^{4,6,8,9,36}$ and three of the four cases reported by Cortner strongly suggest that Giardia interferes with linear growth.

The general impression overall is that children with giardiasis who present to hospital tend to be thin rather than short. The majority of authors are in agreement, however, that the impact of Giardia on growth appears to be most severe in infants and younger children. Thus although these studies concur with the animal data that Giardia infection can affect normal growth and development, all were hospital-based studies and therefore give little guidance as to the importance of this parasite in a community.

Gupta, working in Guatemala, attempted to demonstrate the nutritional impact of Giardia (and Ascaris) by using an interventional chemotherapeutic approach ${ }^{19}$. He randomly allocated 159 children between 2 and 5 years of age to bimonthly therapy with one of four treatment regimens:

(1) piperazine

(2) metronidazole

(3) piperazine plus metronidazole

(4) placebo.

Growth and parasite load were determined at regular intervals during a period of one year. In the study groups receiving metronidazole there was a small but significant increase in height (average $1 \mathrm{~cm}$ ) and an associated fall in the prevalence of Giardia in the stools. Piperazine had no effect on child growth or on the severity of Ascaris infection. However, metronidazole therapy is not monospecific and one cannot assume that the apparent growth-promoting effects were entirely due to its antigiardial properties. One might cautiously suggest that these findings are consistent with earlier studies in hospital-based children that endemic Giardia infection in a rural community may have negative effects on child growth.

It is clear from the ongoing discussion that there is a paucity of knowledge of the natural history of Giardia infection and as yet there have been no prospective longitudinal studies in early life on the impact of Giardia infection on child growth and development. Such data are now difficult to obtain since antimicrobial chemotherapy is now widely available throughout both the developed and developing world and it may now indeed be impossible to obtain such data with any degree of reliability. It would seem important however to establish whether this is 
an important pathogen in infancy and early childhood and thus to determine whether there is a need for instigating more aggressive measures towards biological control.

We have therefore made a detailed examination of the computer data files of the 45 children from the rural highland village of Santa María Cauqué in Guatemala who were observed during the first 3 years of life ${ }^{30}$. Prevalence and incidence data of Giardia infection in these children have been reported previously ${ }^{30.32}$ but we have analysed these unique data files further such that we are able to describe the natural history of Giardia infection from birth through the first 3 years of life and are able to comment on age-related prevalence and incidence, the seasonality of Giardia infection, the association of this infection with diarrhoeal disease and its impact on physical growth ${ }^{17}$.

\section{Natural history of Giardia infection in rural Guatemalan children}

A description of the population studied and the field methodologies used have been reported previously in detail ${ }^{30}$. Essentially the 45 cohort children were visited weekly at home for assessment of growth by anthropometry, disease morbidity and mortality and for the collection of faecal specimens which were subjected to full microbiological examination.

During the first 3 years of life all children excreted Giardia on at least one occasion in the study period. The total number of Giardia events (i.e. Giardia-positive weeks) per cohort child is shown in Figure 9.1. One child had 54 Giardia events, indicating that it was excreting Giardia forms in the stool during 54 of the 156-week study. Prevalence and incidence data were computed using the observed number of child weeks, and rates were expressed per 100 child weeks.

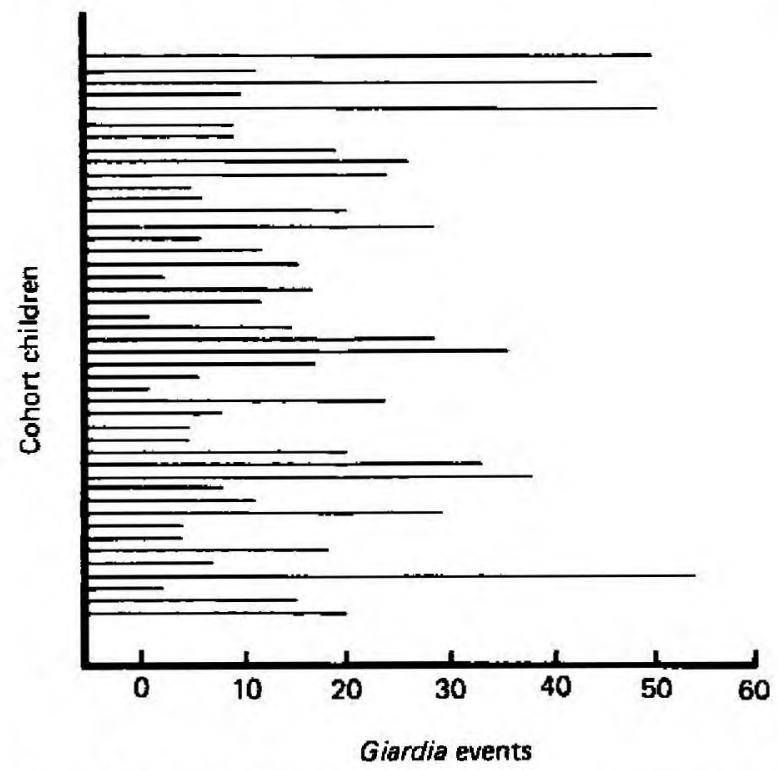

Figure 9.1 The children of Santa Maria Cauqué; total number of Giardia events (i.e. Giardia-positive weeks) per cohort child during the first 3 years of life. 


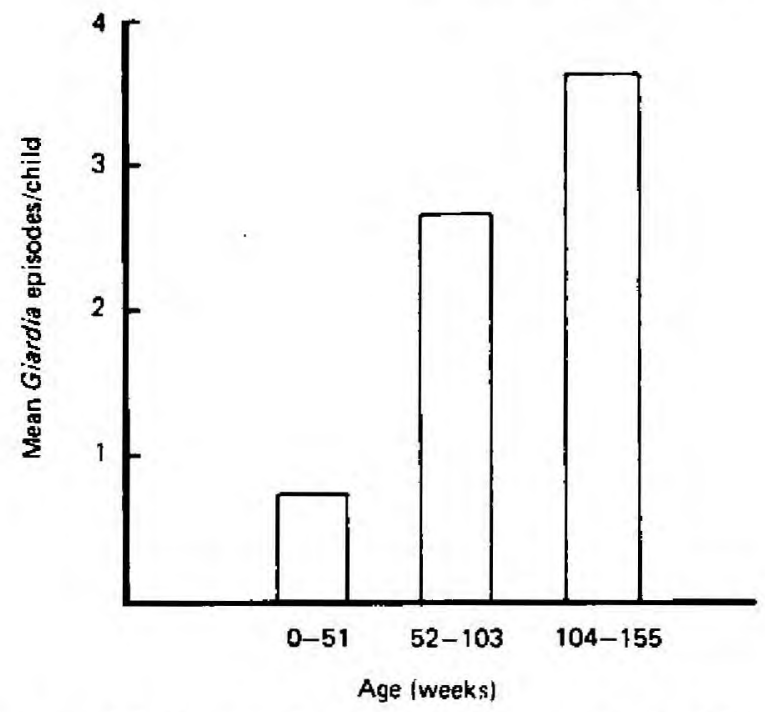

Figure 9.2 Mean Giardia episodes (i.e. separate Giardia infections) per cohort child during the first 3 years of life.

Prevalence and incidence rates of Giardia events were low in the first trimester (both being 0.7 per 100 child weeks) but increased steadily during the remainder of the 3-year study to 20.2 and 5.3 respectively. Thus rates were highest after weaning in the second and third years of life.

Analysis of Giardia events reflects only the proportion of Giardia-positive weeks experienced by these children and does not indicate how many separate Giardia infections each individual sustained during this period. Figure 9.2 shows the mean number of Giardia episodes experienced by cohort children during the first 3 years

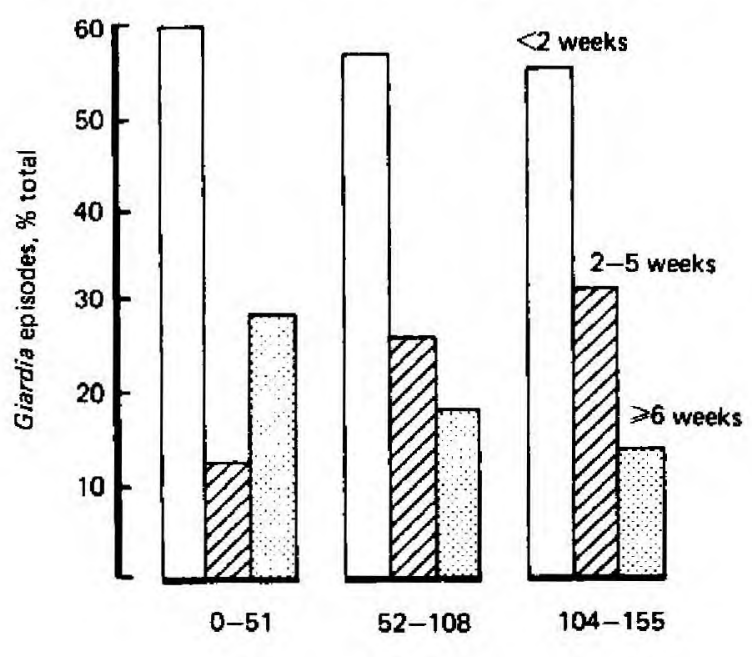

Age (weeks)

Figure 9.3 Duration of Giardia infections in cohort children during the first 3 years of life. 


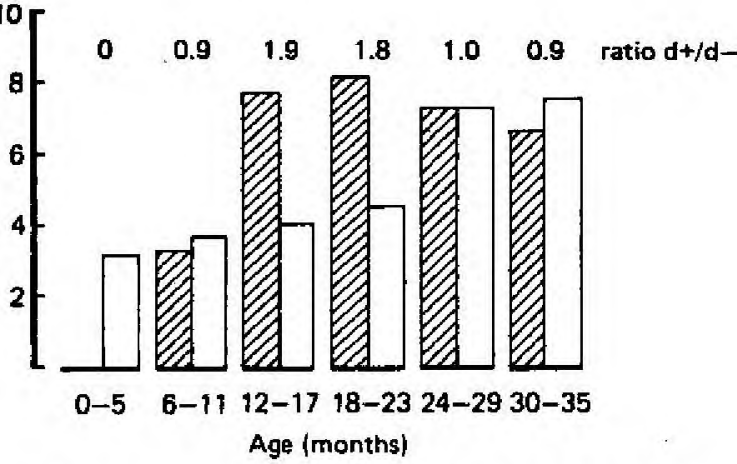

Figure 9.4 Association of diarrhoeal illness with Giardia infections during the first 3 years of life: Giardia episodes with $\mathbb{Z}(\mathrm{d}+)$ and without $\square(\mathrm{d}-$ ) diarrhoea.

of life. Giardia episodes were considered to be different infections when consecutive Giardia-positive stools were separated by a period of at least 2 weeks during which there had been a minimum of three Giardia-negative stools. The mean number of episodes per child increased progressively throughout the 3-year period. Approximately half of these episodes lasted less than 2 weeks in duration (Figure 9.3); however, 28\% of Giardia episodes in the first year of life lasted 6 weeks or more.

During the first semester none of the Giardia episodes were associated with diarrhoea although in the second year of life Giardia episodes associated with diarrhoea exceeded those which were not associated with diarrhoea by a factor of approximately two (Figure 9.4).

\section{Giardia infection and physical growth}

To examine the effect of Giardia on physical growth, weight and height velocities expressed as percentages of the 50th percentile of the National Center of Health Statistics (NCHS) were compared in Giardia-positive and Giardia-negative children during each of the first 3 years of life. Weight velocity was significantly lower in Giardia-positive (median. 53\% NCHS standard) than in Giardia-negative children ( $79 \%$ NCHS standard; $P=0.03$, by Mann Whitney $U$ test) during the second year of life, but weight velocities were similar during the first and third years. As a group, height velocities were not significantly different in children with and without Giardia infection.

However, analysis of growth velocities during the second year of life showed that children who suffered more prolonged Giardia episodes lasting 2 weeks or more tended to have lower median weight and height velocities although significance was only achieved for height velocity in children who had suffered two Giardia episodes. The association of diarrhoea with Giardia episodes seemed to be particularly important, for children who had one, two or three diarrhoea-associated Giardia episodes had significantly lower median height velocities $(50-60 \%$ NCHS standard) than children who had Giardia episodes without diarrhoea (75\% NCHS standard; $P<0.05$ ). Weight velocities were similar. however, in children with and without diarrhoea-associated Giardia infection. 
This study describes for the first time the natural history of Giardia infection during the first 3 years of life in a rural community. Giardia infection affected all children during this period with progressively increasing prevalence and incidence rates during the 3-year period. Infections often persisted for many weeks and in the second year of life were commonly associated with a diarrhoeal illness. Although these children suffered a multiplicity of infections we were able to demonstrate what appeared to be Giardia-related impairment of growth, particularly during the second year of life. Our observations suggest that both the duration of Giardia infections and their association with a diarrhoeal illness were factors associated with growth retardation. We cannot exclude the possibility however that Giardia excretion was always associated with an as yet undefined pathogen which was the major determinant of growth impairment.

Ideally these population-based observations should be tested in an environment where polymicrobial infection is less prevalent. However, there would clearly be major ethical considerations in performing such a study since in symptomatic children one would be compelled to use antigiardial drugs which would themselves alter the natural history of infection. Thus we consider that although the analysis of these growth data is by no means perfect, it supports the view that growth retardation due to Giardia infection is apparent in this rural community in Guatemala.

\section{Mechanisms of growth retardation}

The pathophysiological mechanisms of growth impairment associated with chronic disease of the intestinal tract, chronic infection and indeed chronic ill-health in general have not been clearly established. A variety of possible mechanisms may be operative during chronic Giardia infection. Anorexia is certainly a feature of both acute and chronic giardiasis and may well be an important factor during the early phases of the illness ${ }^{46}$. Reduction in dietary intake and food avoidance is certainly considered to be a major factor in growth retardation associated with Crohn's disease in childhood since in many instances normal growth patterns can be restored by intensive nutritional support ${ }^{14.26}$. The malaise associated with infection may be another contributory factor by reducing interest in food and drive to eat. Energy requirements during Giardia infection remain totally unexplored. However, many infections are associated with an increase in basal metabolic rate with a concomitant increase in energy requirements ${ }^{16}$.

Impaired intestinal absorption of a broad range of nutrients is a common finding in symptomatic Giardia infection. Malabsorption of fat, xylose and of vitamins A, $B_{12}$ and folic acid have all been reported ${ }^{15}$. The mechanisms involved in the production of intestinal malabsorption in giardiasis have not been clearly determined but early suggestions that the parasite competes significantly for host nutrients or that it forms a significant barrier over the surface of the intestine are untenable. Bacterial overgrowth in the proximal small intestine has been associated with Giardia infection and may well contribute to fat malabsorption which can follow this infection ${ }^{44.45}$. In addition $G$. lamblia trophozoites have been shown to inhibit lipolysis in vitro, although its relevance to intraluminal lipolysis remains to be clarified ${ }^{42}$. Intestinal mucosal damage is well established in giardiasis although the precise mechanism has not been established ${ }^{21.27}$. Infection in mice certainly increases enterocyte turnover, which results in a relatively immature population of 
cells on the villus ${ }^{28}$. Active infection is also associated with mucosal inflammation ${ }^{49}$ which itself may be detrimental to enterocyte function. Finally, the parasite has been shown to invade the mucosa directly ${ }^{38}$ and this again might have deleterious effects on mucosal absorbtive function.

The invasion of the biliary tract by Giardia is reported, with associated cholecystitis and cholangitis ${ }^{11,18}$ although no direct relationship between these events and malabsorption has been established. Pancreatic insufficiency has been associated with giardiasis in childhood ${ }^{7,20}$. Whether this is a result of Giardia infection or merely an unrelated association has not been established.

Additional factors that may contribute to growth retardation in children with giardiasis are enteric protein losses and specific nutrient deficiencies. Severe protein-losing enteropathy has been described during Giardia infection ${ }^{41}$ and may contribute to undernutrition. Specific nutrient deficiency, particularly of zinc, has been proposed as a possible cause of growth retardation and delayed sexual maturation in children with Crohn's disease ${ }^{43}$. Zinc status in children with chronic giardiasis has not been evaluated but in the developing world where zinc status may be marginal or indeed overtly subnormal this might contribute to growth disturbance during this infection.

From the preceding discussion it is clear that we know relatively little about the mechanisms of growth failure associated with chronic infection, chronic gastrointestinal disease and chronic ill-health in general. The role of humoral mediators has been an attractive area to investigate but with respect to conventional growth mediators such as growth hormone and the somatomedins, scientific endeavour has been largely unrewarded. It is possible that there are as yet unknown humoral mediators which may act peripherally by blunting or blocking the end-organ response of conventional growth promoters. This area of biomedical research remains highly speculative but continues to be a great challenge to those working in the field.

\section{Summary and conclusions}

Giardiasis is a worldwide infection affecting children and adults in both the developed and developing world. Current evidence suggests that a substantial proportion of infections, however, pass unnoticed since some individuals excrete Giardia cysts without symptoms, although this is probably more common in adults than in children. Although our knowledge of the parasite itself is increasing there are many unknowns, notably the pathogenesis of intestinal disease and the factors which determine parasite virulence. Impaired host defence, notably the immunodeficiency syndromes, appear to facilitate colonization and prolong infections but other factors pertaining to host susceptibility are largely unexplored.

Data in animals suggest that Giardia infection can interfere with growth, particularly in young animals. There also appear to be species differences which may in part be related to genetic constraints of the host and to strain variation of the parasite. Analysis of the rather limited data in children suggests that Giardia can interfere with linear growth and can commonly interfere with weight gain and even cause weight loss. The only prospective longitudinal study in a rural community that has attempted to answer this question, that of the children of Santa Maria Cauqué, concurs with these comments but the study was not specifically 
designed to examine the effect of a single aetiological agent on growth and thus the analysis has its limitations.

The precise mechanisms whereby chronic infection impairs linear growth remain obscure although in enteric infections, such as that due to Giardia, specific effects on nutrient absorption are likely contributors to the multiplicity of compounding factors. Reduced energy intake and increased energy expenditure will continue to be front runners even when molecular mechanisms are more clearly defined.

It seems reasonable to conclude from the foregoing discussion that Giardia infection does have a significant impact at community level and therefore strategies aimed at controlling infection both by improvements in general hygiene and sanitation and possibly by the introduction of more sophisticated methods of biological control are appropriate.

\section{References}

1. Barlough, J.e. (1979) Canine giardiasis: a review. Journal of Small Animal Practice, 20, 613-623

2. Belosevic, M., FAUbert, G.M.. Maclean, J.D.. LAW, c. and crot.l. N.A. (1983) Giardia lamblia infections in Mongolian gerbils: An animal model. Journal of Infectious Diseases, 147, 222-226

3. Bemrick. w.J. (1943) Observations on dogs infected with Giardia. Journal of Parasitology, 49. 1031-1032

4. BoE, J. and RINVIK, R. (1943) Infection with Lamblia intestinalis in children: its clinical significance and treatment. Acsa Paediatrica, 31, 125-146

5. BOx, E.D. (1981) Observations on Giardia in budgerigars. Journal of Protozoology, 28, 491-494

6. BuRke, 3.A. (1975) Giardiasis in childhood. American Journal of Diseases of Children, 129, $1304-1310$

7. CHAWLA, L.S., SEHGAL, A.K., BROOR, S.L., VERMA, R.S. and CHUTTANI, P.N. (1975) Tryptic activity in the duodenal aspirate following a standard test meal in giardiasis. Scandinavian Journal of Gastroenterology, 10. 445-447

8. CORTner, J.A. (1959) Giardiasis: A cause of celiac syndrome. American Journal of Diseases of Children, $98,311-316$

9. COURT, J.M. and ANDERSON, C.M. (1959) The pathogenesis of Giardia lamblia in children. Medical Journal of Australia, 46. 436-438

10. CRAIGE, J.E. (1948) Differential diagnosis and specific therapy of dysenteries in dogs. Journal of the American Veterinary Medicine Association, 113. 343

11. DE MURo, P. (1939) Clinical aspects of giardiasis. Acra Medica Scandinavica, 99. 78-91

12. EULER, A.R. and AMENT, M.E. (1977) Celiac sprue and Crohn's disease-an association causing severe growth retardation. Gastroenterology, 72, 729-731

13. FANTHAM, H.B. and roRTER. A. (1916) The pathogenicity of Giardia lamblia intestinalis from man to experimental animals. Brirish Medical Journal, H. 139-141

14. Fakthing, M.J.g. (1983) Gastrointestinal dysfunction in inflammatory bowel disease. Clinical Nutrition, 2, 5-11

15. Fakthing, M.J.g. (1984) Giardiasis: Pathogenesis of chronic diarrhea and impact on child growth and development. In Chronic Diarrhea in Children. Ed. Lebenthal, E. New York: Raven Press. pp. 253-267

16. Farthing, M.J.g. and Keusch, G.T. (1985) Infection and nutrition. In Paediatric Nutrition. Ed. Metcoff, J. and Arneil, G.C. UK: Butterworth \& Co. pp. 194-218

17. FARTHING, M.J.G., MATA, L.J., URRUTIA, J.s. and KRONMAL, R.A. (1986) Natural history of Giardia infection of infants and children in rural Guatemala and its impact on physical growth. American Journal of Clinical Nutrition, 43, 393-403

18. Goldstein, F., THORNTON, J.J. and SzYolowskı, T. (1978) Biliary tract dysfunction in giardiasis. American Journal of Digestive Diseases, 23, 559-560

19. GUPTA, M.c. (1980) Intestinal parasitic infections and malnutrition. Indian Paediatrics, 47, 503-509

20. GuFtA, R.X. and MEHTA, S. (1973) Giardiasis in children: A study of pancreatic functions. Indian Journal of Medical Research, 61, 743-748

21. hartong, W.M., gourley, W.K. and arVanitakis, c. (1979) Giardiasis; clinical spectrum and functional-structural abnormalities of the small intestinal mucosa. Gastroenterology, $77,61-69$

22. HEWL.ET, E.1., ANDREWS, J.S., RUFFIER, J. and SCHAEFER, F.W. (1982) Experimental infection of mongrel dogs with Giardia lamblia cysts and cultured trophozoites. Journal of Infectious Diseases, $145,89-93$ 
23. HILL, D.R., GUERRANT, R.L., PEARSON, R.D. and HEWLETT, E.L. (1983) Giardia lamblia infection in suckling mice. Journal of Infectious Diseases, 147, 217-221

24. JAMES, J.W. (1972) Longitudinal study of the morbidity of diarrhoeal and respiratory infections in malnourished children. American Journal of Clinical Nutrition, 25, 690-694

25. KAY, R., BARNES, G.L. and TOWNLEY, R.R.W. (1977) Giardia lamblia infestation in 154 children. Australian Paediatric Journal, 13, 98-104

26. KIRschNer, B.s. (1983) Growth retardation in Crohn's disease: The merits of aggressive nutritional therapy. Clinical Nutrition, 2, 26-28

27. LEVINSON, J.D. and NASTRo, L.J. (1978) Giardiasis with total villous atrophy. Gastroenterology, 74 , 271-275

28. MACDONALD, T.T. and FERGUSON, A. (1978) Small intestinal epithelial cell kinetics and protozoal infection in mice. Gastroenserology, 74, 496-500

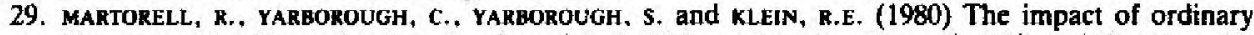
illnesses on the dietary intakes of malnourished children. American Journal of Clinical Nurrition, 33 , 345-350

30. Mata, L.J. (1978) The Children of Santa Maria Cauqué. Cambridge, USA: MIT Press

31. MATA, L.J., URRUTIA, J.J. and LECHTIG, A. (1971) Infection and nutrition of children of a low socioeconomic rural community. American Journal of Clinical Nutrition, 24. 249-259

32. MATA, L.J., URRUTRA, J.J., CACERES, A. and gUZMAN, m.A. (1972) The biological environment in a Guatemalan rural community. In Proceedings of the Western Hemisphere Nutrition Congress $I I I$, Mount Kisco. New York: Future Publishing Co. pp. 257-264

33. MCCAFFERY, T.D., NASk, K., L.AWRENCE, A.M, and KIRSNER, J.B. (1970) Severe growth retardation in children with inflammatory bowel disease. Paediatrics, 45. 386-393

34. MILLEk. R. (1926) Lambliasis as a cause of chronic enteritis in children. Archives of Disease in Childhood, 1, 93-98

35. PERKINS, H. (1921) British Medical Journal, 1, 364 (letter)

36. PUGH, R.J. and NEWTON, R.W. (1980) Giardiasis in infancy and childhood. The Practitioner, 224, 393-397

37. ROBERTS-THOMSON, I.C., STEVENS, D.P., MAkMOUD, A.A.F. and WARREN. K.S. (1976) Gjardiasis in the mouse: an animal model. Gastroenterology, 71, 57-61

38. SAHA, T.K. and GHosh, т.K. (1977) Invasion of small istestinal mucosa by Giardia lamblia. Gastroenterology, 72, 402-405

39. SCHLeinitz, P., JUSTUS, P., STENZEL, P., OWEN, R. and MEYer. E. (1983) Successful introduction of culture adapted Giardia into a rabbit model: ultrastructural features. Gastroenterology, 84, 1301 (abstract)

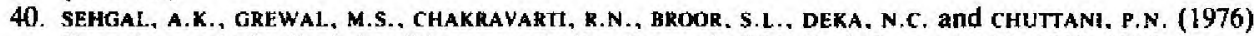
Experimental giardiasis in albino rats. Indian Journal of Medical Research, 64. 1015-1018

41. SHerman, P. and Liebman. W.M. (1980) Apparent protein-losing enteropathy associated with giardiasis. American Journal of Diseases of Children, 134, 893-894

42. SMITH, P.D., HORSBURGH, C.R. and BROWN, w,R. (1981) In virro studies on bile acid deconjugation and lipolysis inhibition by Giardia lamblia. Digestive Diseases and Sciences, 26. 700-704

43. SOLomons, N.W. and RosengERG, I.H. (1981) Zinc and infammatory bowel disease. American Journal of Clinical Nutrition, 34, 1447-1448

44. TANDON, B.N., TANDON, R.K., SATPATHY, B.K. and SHRINIWAS, a. (1977) Mechanism of malabsorption in giardiasis: a study of bacterial fiora and bile salt deconjugation in upper jejunum. Gur, 18 , $176-181$

45. TOMKINS, A.M., DRASAR, B.S., BRADLEY, A.K. and wILLIAMSON, W.A. (1978) Bacterial colonisation of jejunal mucosa in giardiasis. Transacsions of the Royal Society of Tropical Medicine and Hygiene, $72,33-36$

46. VEGHELYL, P. (1938) Giardiasis in children. American Journal of Diseases of Children. $56.1231-1241$

47. Verkasalo, M., KUITUNeN, P., Leisti, S and PERHEentupa, J. (1978) Growth failure from symptomless coeliac disease. Helvetia Paediatrica Acra, 33, 489-495

48. WALZER, P.D.. WOLFE, M.S. and SCHUL.TZ. M.G. (1971) Giardiasis in travellers. Journal of Infectious Diseases, 124, 235-237

49. WRIGHT, S.A. and TOMKINS, A.M. (1977) Quantification of the lymphocytic infiltrate in jejunal epithelium in giardiasis. Clinical and Experimental Immunology, 29. 408-412 
Impreso en la Oficina de Publicaciones de la Universidad de Costa Rica 